\title{
Hypoxia promotes the proliferation of MC3T3-E1 cells via the hypoxia-inducible factor-1 $\alpha$ signaling pathway
}

\author{
LICHAO WANG, BULING WU, YU ZHANG and ZHIHUI TIAN \\ Department of Stomatology, Nanfang Hospital, College of Stomatology, \\ Southern Medical University, Guangzhou, Guangdong 510515, P.R. China
}

Received April 15, 2014; Accepted June 3, 2015

DOI: $10.3892 / \mathrm{mmr} .2015 .4034$

\begin{abstract}
Investigations into the role of hypoxia have concentrated on hypoxic damage to cells and the associated adaptative mechanisms, however, the effects of hypoxia on cell proliferation and differentiation have received less attention. The present study aimed to investigate the role of hypoxia on the proliferation of MC3T3-E1 cells and examine the molecular mechanism involved. Cells treated with low levels of hypoxia had an increased percentage of $\mathrm{S}$ phase cells and a decreased percentage of G1 phase cells, promoted the level of cell proliferation-associated proteins, proliferating cell nuclear antigen and cyclin D. In addition, hypoxia increased cell proliferation by upregulating the expression of hypoxia-inducible factor (HIF)-1 $\alpha$. The phosphoinositide 3-kinase/Akt and mitogen-activated protein kinase/extracellular signal-regulated kinase pathways augmented the expression of HIF-1 $\alpha$ in the MC3T3-E1 cells. The present study demonstrated that hypoxia induces positive effects on osteoblast proliferation, suggesting a novel strategy in the treatment of osteoporosis.
\end{abstract}

\section{Introduction}

Osteoporosis, a widespread skeletal disease, is more common with advancing age and remains a major public health problem

Correspondence to: Mr. Buling Wu, Department of Stomatology, Nanfang Hospital, College of Stomatology, Southern Medical University, 1838 North Guangzhou Road, Baiyun Ave., Guangzhou, Guangdong 510515, P.R. China

E-mail: yangy2014_3@163.com

Abbreviations: $\alpha$-MEM, $\alpha$-minimalessential medium;PI,propidium iodide; DMSO, dimethylsulfoxide; PI3K, phosphoinositide 3-kinase; FITC, fluorescein isothiocyanate; PBS, phosphate-buffered saline; HIF, hypoxia-inducible factor; TBS, Tris-buffered saline; PDF, peritoneal dialysis fluid; MAPK, mitogen-activated protein kinase; ERK, extracellular signal-regulated kinase

Key words: MC3T3-E1, proliferation, hypoxia-inducible factor-1 $\alpha$, phosphoinositide 3-kinase, Akt, mitogen-activated protein kinase, extracellular signal-regulated kinase due to its association with low bone mineral density (BMD) and pathological fractures (1). Osteoporosis is defined as a BMD value of $\geq 2.5$ standard deviations below the average for young adult women by the World Health Organization (2). The pathological consequence of osteoporosis is fracture and annually, 1,500,000 fractures are attributable to osteoporosis in the USA (3). Osteoporosis is more prevalent in the East due to the Asian population having a lower body mass index (BMI), shorter height, lack of physical activity and low dietary calcium intake (4). The scientific pathogenesis of osteoporosis and therapeutic management options for osteoporosis have been investigated, with progress in studies of antiresorptive or anabolic therapeutic drugs, however, the underlying mechanisms and treatments of osteoporosis remain to be elucidated.

An adequate supply of oxygen and nutrients is essential for cell survival and metabolism. Hypoxia, which is defined as the reduction or lack of oxygen in organs, tissues or cells, has been suggested to contribute to a number of pathologies, including rheumatoid arthritis, cancer and lung disease (5-7). For cells, hypoxia is important in growth inhibition, oxidative stress and apoptosis (8). The role of hypoxia in cell proliferation, particularly in osteoblasts, remains to be elucidated. The present study hypothesized that each tissue and cell type may have a different ability to adapt to hypoxic condition and have potential self-protection mechanisms. Low levels of hypoxia may act as a signal to induce cell potential. The activation and proliferation of osteoblasts is an important factor for the treatment of osteoporosis. The present study aimed to investigate the role of hypoxia on cell proliferation in MC3T3-E1 cells and examine the underlying molecular mechanism.

\section{Materials and methods}

Reagents. $\alpha$-minimal essential medium ( $\alpha$-MEM), penicillin-streptomycin, Triton X-100 and dimethyl sulfoxide (DMSO), Hoechst 33342 and EDTA were purchased from Sigma-Aldrich (St. Louis, MO, USA). Antibodies against extracellular signal-regulated kinase [ERK; mouse monoclonal immunoglobulin (Ig)G2a; no sc-514302], phosphorylated (p)-ERK (mouse monoclonal IgG1; no. sc-377400), Akt (mouse monoclonal IgG1; sc-377457), p-Akt (rabbit polyclonal IgG; sc-135650), proliferating cell nuclear antigen (PCNA; mouse monoclonal IgG2a; sc-25280) 
and anti- $\beta$-actin (mouse monoclonal antibody C4; sc-47778) were purchased from Santa Cruz Biotechnology, Inc. (Dallas, TX, USA) and antibodies against hypoxia-inducible factor (HIF)-1 $\alpha$ (rabbit monoclonal IgG; 1:400 dilution; no. 14179) and cyclin D1 (rabbit monoclonal antibody; no. 2978) were purchased from Cell Signaling Technology, Inc. (Danvers, MA, USA). All the reagents were trace element analysis grade and water was glass distilled.

Cell culture and hypoxia culture conditions. Osteoblastic MC3T3-E1 cells (cat. no. CRL-2593; American Type Culture Collection, Manassas, VA, USA) were cultured in $\alpha$-MEM supplemented with $10 \%$ fetal bovine serum (FBS; Gibco-BRL, Invitrogen Life Technologies, Carlsbad, CA, USA) and $1 \%$ penicillin-streptomycin at $37^{\circ} \mathrm{C}$ in a $5 \% \mathrm{CO}_{2}$ incubator. The cells were subcultured every 3 days with $0.2 \%$ trypsin and $0.02 \%$ EDTA. For experiments, the cells were cultured for $24 \mathrm{~h}$ to obtain monolayers in $3 \mathrm{ml} \alpha$-MEM with $10 \% \mathrm{FBS}$. The cells were incubated under various $\mathrm{O}_{2}$ concentrations, $20 \%$ (normoxia), 10, 5 and 0\% (hypoxia), in small individual culture chambers [BPN-240CRH (UV); Shanghai Yiheng Scientific Instrument Co., Shanghai, China]. The chambers were filled with a non-standard gas mixture, containing the indicated $\mathrm{O}_{2}$ level and $5 \% \mathrm{CO}_{2}$ in a $\mathrm{N}_{2}$ base.

Assessment of cell viability. Cell viability was measured using an MTT assay in 96-well plates. Briefly, the cells were seeded at 5,000 cells/well $(100 \mu \mathrm{l})$ and cultured with $20,10,5$ or $0 \% \mathrm{O}_{2}$ for $0-72 \mathrm{~h}$. Subsequently, $10 \mu \mathrm{l} \mathrm{MTT}$ solution $(5 \mathrm{mg} / \mathrm{ml})$ was added to the medium and incubated at $37^{\circ} \mathrm{C}$ for $3 \mathrm{~h}$. The MTT solution was removed and $100 \mu \mathrm{l}$ DMSO was added to dissolve the colored formazan crystals for $15 \mathrm{~min}$. The absorbance was measured at $490 \mathrm{~nm}$ using a Sunrise RC microplate reader (Tecan Group, Ltd., Männedorf, Switzerland). The relative cellular growth was determined using a ratio of the average absorbance in the treated cells, vs. the average absorbance in the control cells.

Detection of the cell cycle. The MC3T3-E1 cells were cultured with 20,10 or $0 \% \mathrm{O}_{2}$ for $48 \mathrm{~h}$ and the cell cycle phases were analyzed using fluorescent activated cell sorting (FACS). The cells were collected and fixed in $70 \%$ pre-cooled ethanol $\left(4^{\circ} \mathrm{C}\right)$ overnight. The cells were then washed and centrifuged in phosphate-buffered saline (PBS) at $150 \mathrm{xg}$ for $5 \mathrm{~min}$ prior to resuspending in $0.5 \mathrm{ml} 1 \%$ RNase (Beyotime Institute of Biotechnology, Haimen, China) at $37^{\circ} \mathrm{C}$ for $30 \mathrm{~min}$ and staining with propidium iodide $(50 \mu \mathrm{g} / \mathrm{ml}$; Sigma-Aldrich). Cell cycle analysis was performed to determine the G1 phase and the cell cycle distribution. The DNA content and the cell cycle were analyzed using a flow cytometer (FACSCalibur; BD Biosciences, Franklin Lakes, NJ, USA).

Western blotanalysis. The total cell extracts and nuclear extracts were prepared, as described previously (9). The cellular proteins (50 $\mu \mathrm{g})$ were electrophoresed and blotted onto a polyvinylidene difluoride membrane. The membrane was blocked with $5 \%$ nonfat milk in Tris-buffered saline containing $25 \mathrm{mM}$ Tris and $0.15 \mathrm{M} \mathrm{NaCl}$ (pH 7.4) containing 0.1\% Tween-20 (TBS-T) for $1 \mathrm{~h}$, prior to incubating the membrane with specific primary antibodies for $1 \mathrm{~h}$. The following primary antibodies were used: Anti-ERK (1:400), anti-p-ERK (1:400), anti-Akt (1:400), anti-p-Akt (1:400), anti-PCNA (1:400), anti- $\beta$-actin, anti-HIF-1 $\alpha$ (1:400) and anti-cyclin D1 (1:400). The membrane was washed three times with TBS-T for $10 \mathrm{~min}$ and was then incubated with the secondary antibodies [horseradish peroxidase (HRP)-conjugated goat anti-mouse IgG; sc-2005; or HRP-conjugated goat anti-rabbit IgG; sc-2004; both from Santa Cruz Biotechnology, Inc.]. Following another three washes with TBS-T for $10 \mathrm{~min}$ each, the membranes were incubated with enhanced chemiluminescence reagent for horseradish peroxidase (Super-Signal West Femto Maximum Sensitivity Substrate; Pierce Biotechnology, Inc., Rockford, IL, USA) for $30 \mathrm{sec}$ and exposed to an autoradiography film for visualization of the bands using the LAS-3000 luminescent image analyzer (Fuji Photo Film Co., Ltd., Tokyo, Japan). The relative quantities of the various proteins were analyzed and the results were quantified using Quantity One software V4.62 (Bio-Rad, Hercules, CA, USA).

Fluorescence microscopy. The MC3T3-E1 cells were seeded into six-well plates at 100000 cells/well $(2,000 \mu \mathrm{l})$ and cultured with 20,10 or $0 \% \mathrm{O}_{2}$ for $48 \mathrm{~h}$. The cells were then washed once with ice-cold PBS $\left(4^{\circ} \mathrm{C}\right)$ and fixed using $4 \%$ paraformaldehyde for $30 \mathrm{~min}$. The cells were washed with PBS three times and incubated with $1 \%$ Triton X-100 for $10 \mathrm{~min}$. The cells were blocked at non-specific antibody binding sites by incubating with $10 \%$ goat serum in PBS containing $0.3 \%$ Triton $\mathrm{X}-100$ and $0.5 \%$ bovine serum albumin for $30 \mathrm{~min}$ at room temperature. The cells were then incubated with mouse monoclonal antibody against HIF-1 $\alpha$ (1:400 in PBS) overnight. Tetramethylrhodamine-conjugated goat anti-mouse immunoglobulin G (1:100 in PBS) was added for $30 \mathrm{~min}$ at room temperature and Hoechst33342 was then added to the cells for $15 \mathrm{~min}$. Subsequently, the cells were washed three times with PBS and were visualized by fluorescence microscopy (TCS SP5 II; Leica Microsystems, Wetzlar, Germany).

HIF-la overexpression plasmidtransfectionand smallinterfering RNA (siRNA). To induce the overexpression of HIF-1 $\alpha$, a plasmid (HIF-1 $\alpha$-pcDNA3.1/myc-hisA) expressing a full-length HIF-1 $\alpha$ cDNA gene was transiently transfected using Lipofectamine 2000 (Invitrogen Life Technologies). siRNA targeting HIF-1 $\alpha$ was prepared by Invitrogen Life Technologies. The sequence of the siRNA, targeting a specific sequence in ZnT7 mRNA, was 5'-AGTTCACCTGAGCCTAATA-3' and the scrambled siRNA sequence was 5'-UUGGCUUCGUGACUAUGGCTT-3'. The target sequences of the HIF-1 $\alpha$ siRNA were identified using BLAST, searched against the GenBank database (http://www. ncbi.nlm.nih.gov/genbank/; ID SI02664053). All transfection experiments were performed in independent triplicates according to the manufacturer's instructions for Lipofectamine 2000. The cells were allowed to recover in $\alpha$-MEM for $24 \mathrm{~h}$ following transfection.

RNA extraction and reverse transcription quantitative polymerase chain reaction $(R T-q P C R)$. The total RNA was isolated from the cells using TRIzol reagent (Invitrogen Life Technologies) according to the manufacturer's instructions. A Protein-Nucleic Acid Analyzer (GeneQuant Pro DNA/RNA; GE Healthcare, Little Chalfont, UK) was used to determine 
A

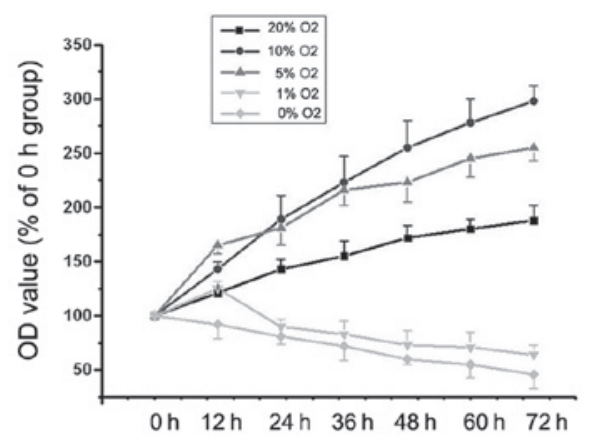

C

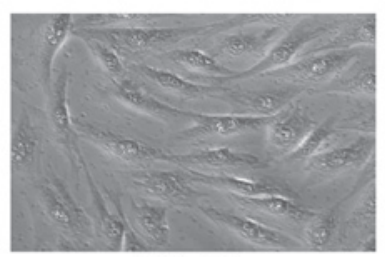

$20 \%$ O2

D
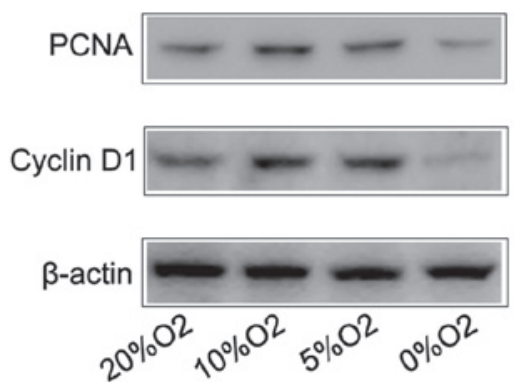

B
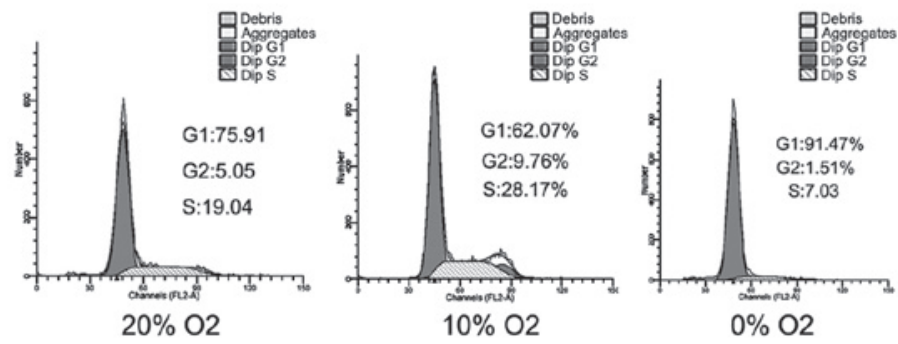

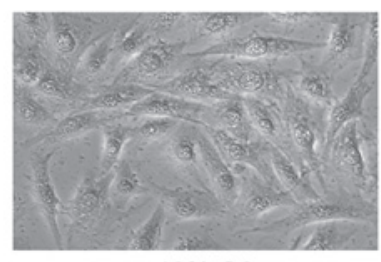

$10 \% \mathrm{O} 2$

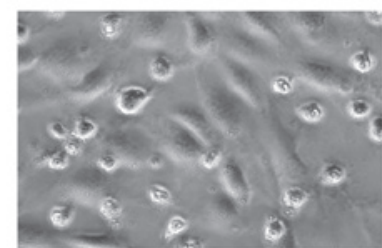

$0 \% \mathrm{O} 2$

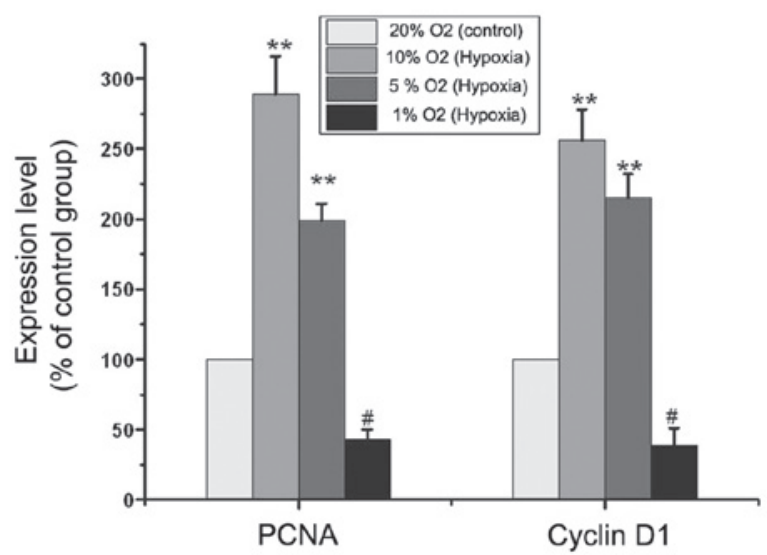

Figure 1. Hypoxia promotes MC3T3-E1 cell proliferation. (A) MC3T3-E1 cells were cultured in 20, 10, 5 or $0 \% \mathrm{O}_{2}$ for $0-72 \mathrm{~h}$ and cell viability was analyzed using a 3-(4,5-dimethylthiazol-2-y)-2,5-diphenyltetrazolium bromide assay. The data are expressed as the mean \pm standard deviation of three independent experiments. (B) The cells were cultured in 20,10 or $0 \% \mathrm{O}_{2}$ for $48 \mathrm{~h}$ and cell cycle phases were analyzed using fluorescent activated cell sorting. (C) Cells were treated, as described above, and cell morphology was observed by microscopy (magnification, $\mathrm{x} 400$ ). (D) Cells were cultured in $20,10,5$ or $0 \% \mathrm{O}_{2}$ for $48 \mathrm{~h}$ and the expression levels of PCNA and cyclin D1 were detected using western blot analysis. The results represent three independent experiments. $\beta$-actin was used as a loading control. Values are expressed as the mean \pm standard error of the mean. ${ }^{* *} \mathrm{P}<0.01$ and ${ }^{*} \mathrm{P}<0.01$, vs. 20\% $\mathrm{O}_{2}$ group. OD, optical density; PCNA, proliferating cell nuclear antigen.

the concentration and quality of total RNA extracted. cDNA synthesis and PCR detection were performed using a PCR instrument (PTC-200; Bio-Rad) according to the manufacturer's instructions of the PrimeScript ${ }^{\mathrm{TM}}$ RT-PCR kit (Takara Bio, Inc., Otsu, Japan). The sequences of the HIF-1 $\alpha$ and GAPDH genes were obtained from the GenBank database and specific primers were designed over an exon-exon junction using Primer Premier 5.0 software (Premier Biosoft, Palo Alto, CA, USA). The following primers were used: GAPDH forward, 5'-AGCAGTCCCGTACACTGGCAAAC-3' and reverse, 5'-AGCAGTCCCGTACACTGGCAAAC-3'; HIF-1 $\alpha$ forward, 5'-GACAATAGCTTCGCAGAATGC-3' and reverse, 5'-TCGTAACTGGTCAGCTGTGG-3'. RT-qPCR was performed using gene-specific oligonucleotides under conditions of linear amplification. The reaction conditions were as follows: $94^{\circ} \mathrm{C}$ for $4 \mathrm{~min} ; 94^{\circ} \mathrm{C}$ for $40 \mathrm{sec}, 50^{\circ} \mathrm{C}$ for $45 \mathrm{sec}$ and $72^{\circ} \mathrm{C}$ for $45 \mathrm{sec}$, for 35 cycles; and followed by a final extension at $72^{\circ} \mathrm{C}$ for $10 \mathrm{~min}$. Electrophoresis (2\% agarose gel; $110 \mathrm{~V}$ for $30 \mathrm{~min}$ ) was performed to separate the PCR products. The RT-qPCR products were stained with ethidium bromide and visualized with ultraviolet light. A gel imaging system (FluorChem FC2; Alpha Innotech, Palo Alto, CA, USA) was used to capture images.

Statistical analysis. Data are expressed as the mean \pm standard error of the mean. Statistical comparisons were made by analysis of variance and individual comparisons were made using Tukey's multiple comparison test. $\mathrm{P}<0.05$ was considered to indicate a statistically significant difference.

\section{Results}

Low levels of hypoxia promotes the proliferation of MC3T3-E1 cells. To investigate the role of hypoxia on cell proliferation, 
A
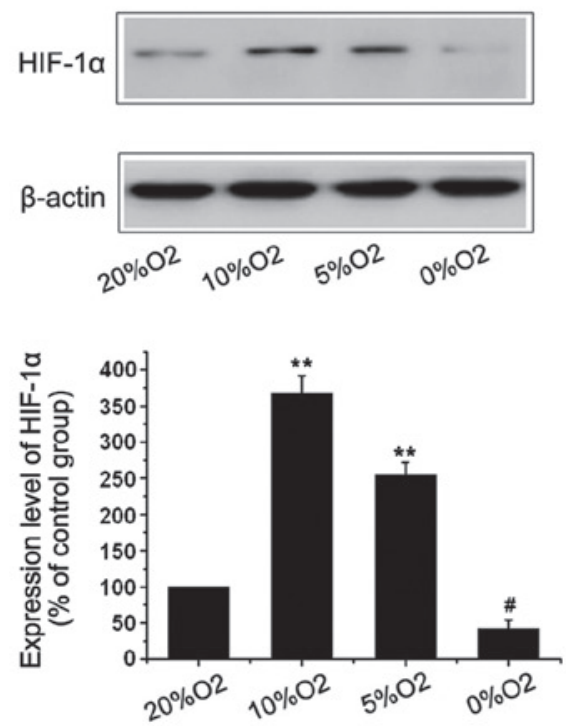

C

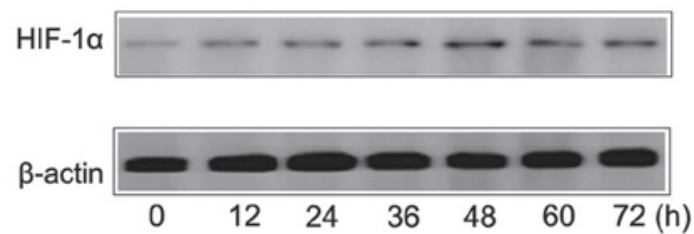

B

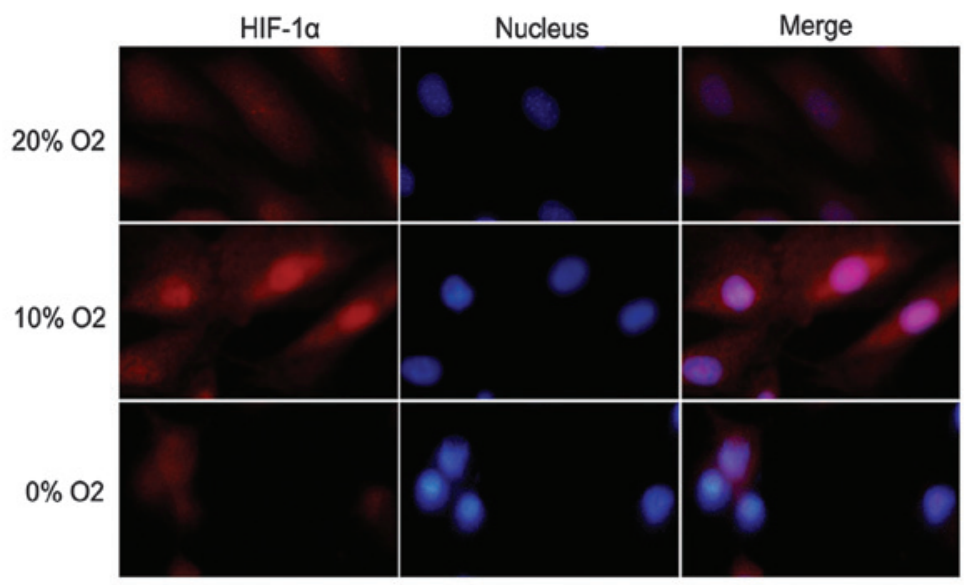

D

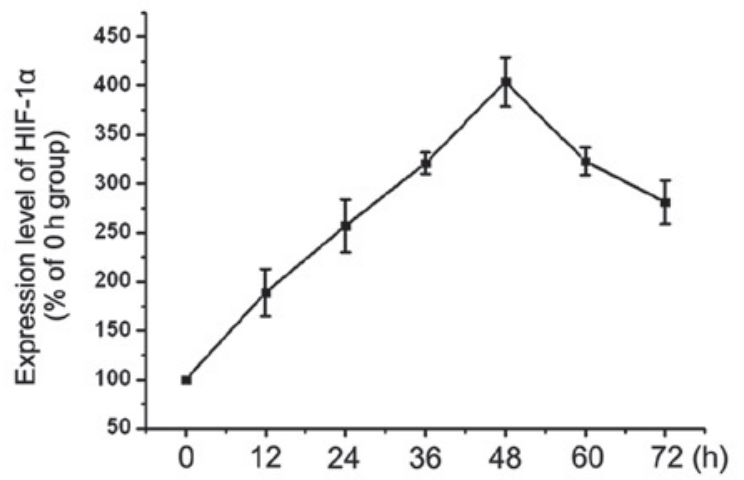

Figure 2. Hypoxia increases the expression of HIF-1 $\alpha$ in MC3T3-E1 cells. (A) MC3T3-E1 cells were cultured in 20, 10, 5 or $0 \% \mathrm{O}_{2}$ for $48 \mathrm{~h}$ and the expression of HIF-1 $\alpha$ was detected by western blot analysis. The results represent three independent experiments. $\beta$-actin was used as loading control. ("* $\mathrm{P}<0.01$, vs. $20 \% \mathrm{O}_{2}$ group). (B) Cells were cultured in 20,10 or $0 \% \mathrm{O}_{2}$ for $48 \mathrm{~h}$ and the HIF-1 $\alpha$ protein was stained and observed by fluorescent microscopy (magnification, x400). (C) MC3T3-E1 cells were cultured in $10 \% \mathrm{O}_{2}$ for $0,12,24,36,48,60$ and $72 \mathrm{~h}$ and the expression of HIF-1 $\alpha$ was detected using western blot analysis. (D) Results represent three independent experiments. $\beta$-actin was used as a loading control. Values are expressed as the mean \pm standard error of the mean. HIF, hypoxia-inducible factor.

the MC3T3-E1 cells were cultured with various concentrations of $\mathrm{O}_{2}$ for $1-72 \mathrm{~h}$ and the cell viability was detected using an MTT assay. As shown in Fig. 1A, a low level of hypoxia $\left(10\right.$ or $\left.5 \% \mathrm{O}_{2}\right)$ promoted cell proliferation in a time-dependent manner, while severe hypoxia $\left(1\right.$ or $\left.0 \% \mathrm{O}_{2}\right)$ inhibited cell proliferation or induced apoptosis in the cells. The promotion of proliferation under $10 \% \mathrm{O}_{2}$ was more marked. To determine whether the effect on cell proliferation was associated with cell cycle regulation, the cell cycle progression of the MC3T3-E1 cells was investigated. Notably, the number of cells in the $\mathrm{S}$ phase of the cell cycle under low levels of hypoxia $\left(10 \% \mathrm{O}_{2}\right)$ was significantly increased compared with the normoxic group $\left(20 \% \mathrm{O}_{2}\right)$ and severe hypoxia $\left(0 \% \mathrm{O}_{2}\right)$ significantly reduced the number of cells in the $\mathrm{S}$ phase. Light microscopy revealed that low levels of hypoxia promoted cell proliferation and severe hypoxia resulted in apoptotic morphological changes (Fig. 1C). To assess whether low levels of hypoxia were involved in cell proliferation, the levels of proliferation-associated protein, PCNA, and cell cycle protein, cyclin D1, were detected by western blot analysis under different $\mathrm{O}_{2}$ concentrations.
As shown in Fig. 1D, low levels of hypoxia upregulated the expression levels of PCNA and cyclin D1. Conversely, the proteins were markedly decreased in the severe hypoxia cells compared with the control group. In conclusion, low levels of hypoxia were not harmful to the cells and, to a certain extent, may assist in promoting the proliferation of MC3T3-E1 cells.

Hypoxia upregulates the expression of HIF-1 $\alpha$ in MC3T3-E1 cells. In order to investigate whether hypoxia affected the expression of HIF-1, the MC3T3-E1 cells were cultured with $20,10,5$ or $0 \% \mathrm{O} 2$ for $48 \mathrm{~h}$ and the protein expression of HIF-1 $\alpha$ was determined by western blot analysis. As shown in Fig. 2A, the protein expression of HIF-1 $\alpha$ was significantly induced under hypoxia $\left(10 \% \mathrm{O}_{2}\right)$ and reduced under severe hypoxia $\left(0 \% \mathrm{O}_{2}\right)$. Additionally, an increase in the expression of $\mathrm{HIF}-1 \alpha$ at $10 \% \mathrm{O}_{2}$ and a decrease at $0 \% \mathrm{O}_{2}$ were observed by fluorescent microscopy (Fig. 2B). To determine whether the hypoxia-dependent expression of HIF-1 $\alpha$ occurred in a time-dependent manner, the cells were cultured with $10 \% \mathrm{O}_{2}$ for $0,12,24,36,48,60$ and $72 \mathrm{~h}$, and the expression 
A
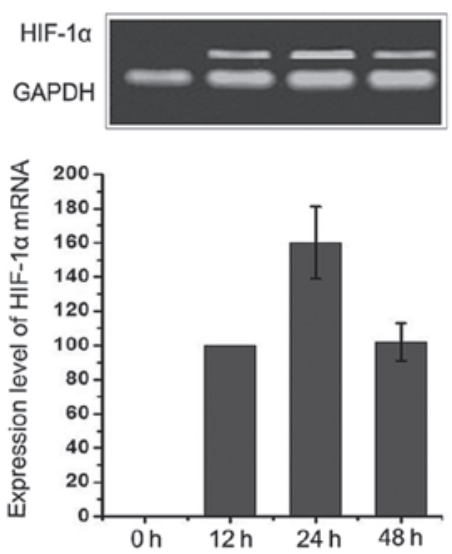

D

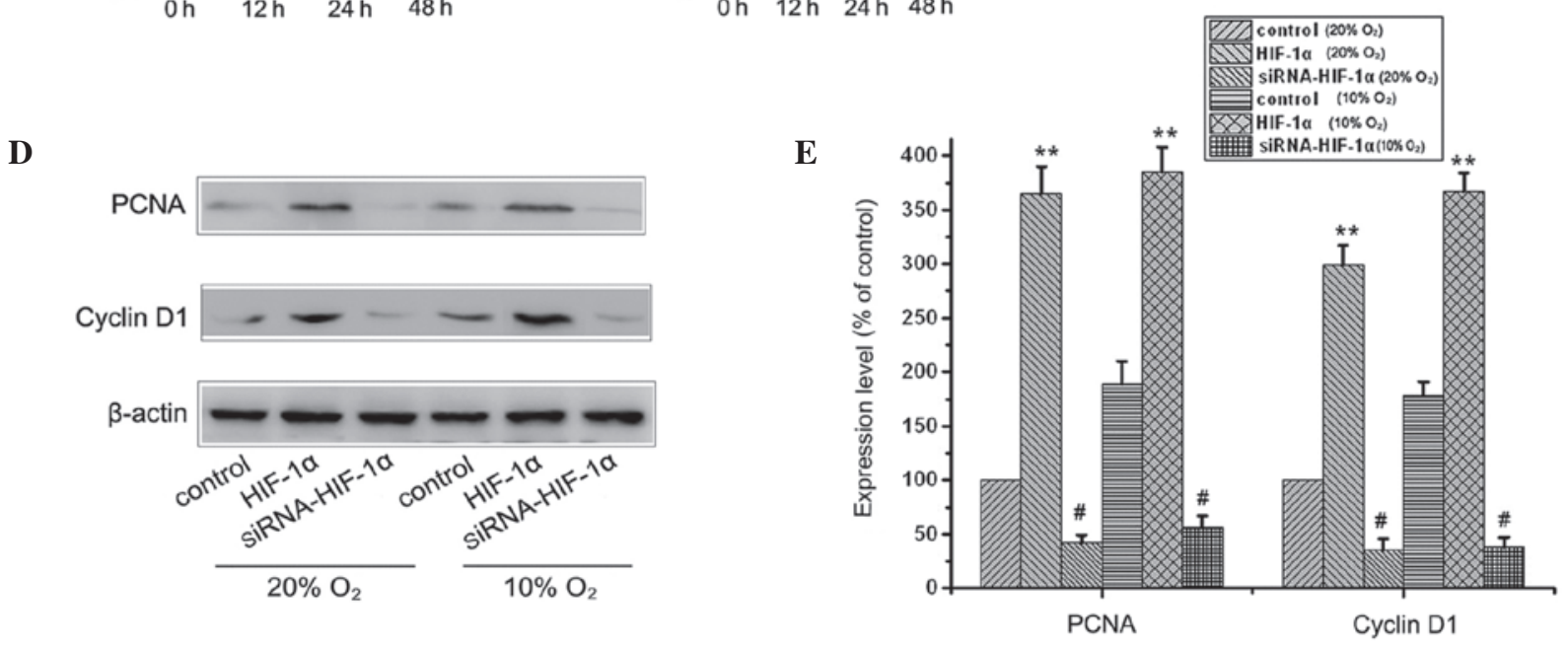

B
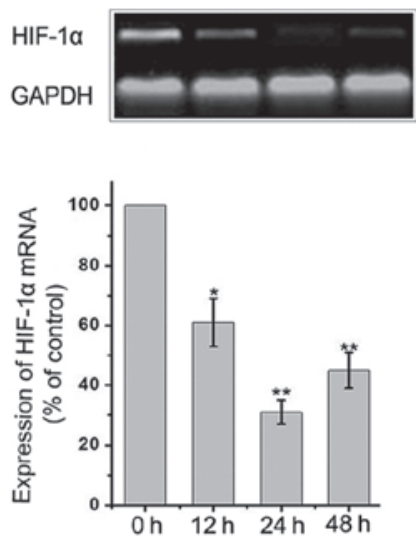

C
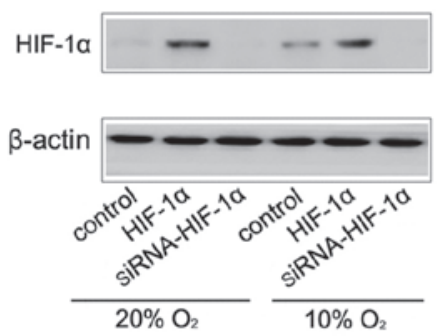

Figure 3. HIF-1 $\alpha$ promotes MC3T3-E1 cell proliferation. (A) RT-qPCR analysis was performed from isolated total RNA to assess the mRNA expression of HIF-1 $\alpha$ following HIF-1 $\alpha$-pcDNA3.1/myc-hisA transfection at various time points. GAPDH was used as an endogenous internal reference gene. The results represent three independent experiments. (B) RT-qPCR analysis was performed from isolated total RNA to assess the mRNA expression of HIF-1 $\alpha$ following HIF-1 $\alpha$-siRNA transfection at various time points. GAPDH was used as an endogenous internal reference gene. The results represent three independent experiments. ( $\mathrm{P}<0.05$ and ${ }^{* *} \mathrm{P}<0.01$, vs. 0 h group). (C) Cells (control group, overexpressing-HIF-1 $\alpha$ group and siRNA-HIF-1 $\alpha$ group) were cultured with 20 or $10 \% \mathrm{O}_{2}$ for $48 \mathrm{~h}$ and the expression of HIF-1 $\alpha$ was detected by western blot analysis. (D) Cells (control group, overexpressing-HIF-1 $\alpha$ group and siRNA-HIF-1 $\alpha$ group) were cultured with 20 or $10 \% \mathrm{O}_{2}$ for $48 \mathrm{~h}$ and the expression levels of PCNA and cyclin D1 were assessed by western blot analysis. (E) Results represent three independent experiments. $\beta$-actin was used as loading control. Values are expressed as the mean \pm standard error of the mean. ${ }^{* *} \mathrm{P}<0.01$ and ${ }^{\#} \mathrm{P}<0.01$, vs. $20 \% \mathrm{O}_{2}$ control group. HIF, hypoxia-inducible factor; si, small interfering; PCNA, proliferating cell nuclear antigen; RT-qPCR, reverse transcription quantitative polymerase chain reaction.

of HIF-1 $\alpha$ was detected using western blot analysis. As shown in Fig. $2 \mathrm{C}$ and D, the expression of HIF-1 $\alpha$ increased in hypoxia $\left(10 \% \mathrm{O}_{2}\right)$, peaked at $48 \mathrm{~h}$ and decreased after $48 \mathrm{~h}$, suggesting an internal mechanism inhibited the further increase in the expression of HIF-1 $\alpha$. However, hypoxia was important in the upregulation of the overall expression of HIF-1 $\alpha$.

Hypoxia promotes cells proliferation via the HIF-1a pathway. Low levels of hypoxia not only increased cell proliferation, but also upregulated the expression of HIF-1 $\alpha$ in the MC3T3-E1 cells. The present study investigated the effect of HIF-1 $\alpha$ on cell proliferation by siRNA knockdown and overexpression of HIF-1 $\alpha$. The effects of HIF-1 $\alpha$ knockdown and the overexpression of HIF-1 $\alpha$ were most marked $48 \mathrm{~h}$ after transient transfection (Fig. 3A-C). The cells in the control, HIF-1 $\alpha$-overexpression and HIF-1 $\alpha$-knockdown groups were cultured in 20 or $10 \% \mathrm{O}_{2}$ and the expression levels of the proliferation-associated protein, PCNA, and cell cycle protein, cyclin D1, were detected by western blot analysis. As shown in Fig. 3C and D, the overexpression of HIF-1 $\alpha$ increased the effect of hypoxia-induced cell proliferation and this activation by hypoxia was significantly reversed by HIF-1 $\alpha$-knockdown, indicating that low levels of hypoxia promoted cell proliferation via the HIF-1 $\alpha$ pathway.

Hypoxia promotes the expression of HIF-1 $\alpha$ via the mitogen-activated protein kinase (MAPK)/ERK and phosphoinositide 3-kinase (PI3K)/Akt pathways. Previous studies have demonstrated that the MAPK/ERK and PI3K/Akt pathways are important in regulating the expression of HIF-1 $\alpha(10,11)$. The present study investigated whether these signaling pathways were involved in regulating the expression of HIF-1 $\alpha$ in the MC3T3-E1 cells under hypoxic conditions. The MC3T3-E1 cells were cultured under different $\mathrm{O}_{2}$ concentrations and the expression levels of ERK, p-ERK, Akt and p-Akt were detected by western blot analysis. The total levels of Akt and ERK remained unchanged under different $\mathrm{O}_{2}$ concentrations. 
$\mathbf{A}$

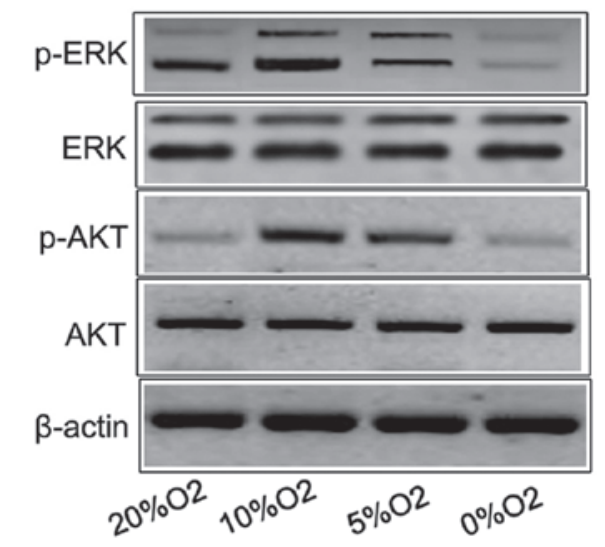

C
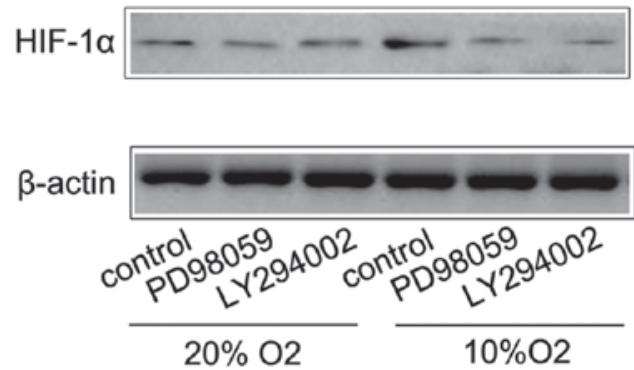

B

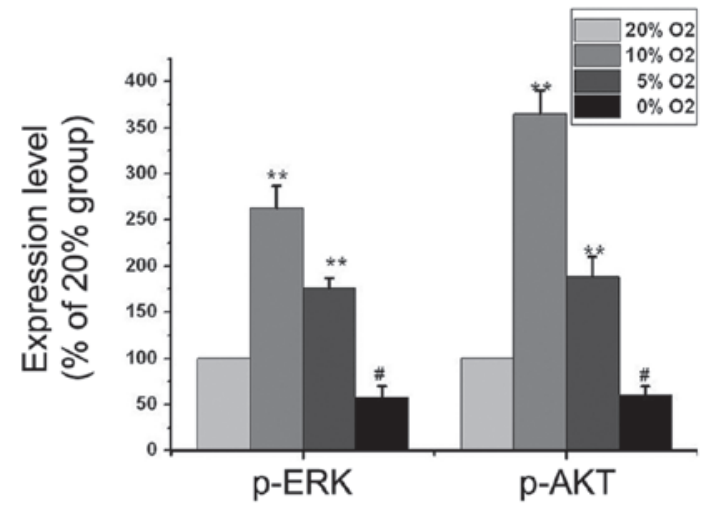

D

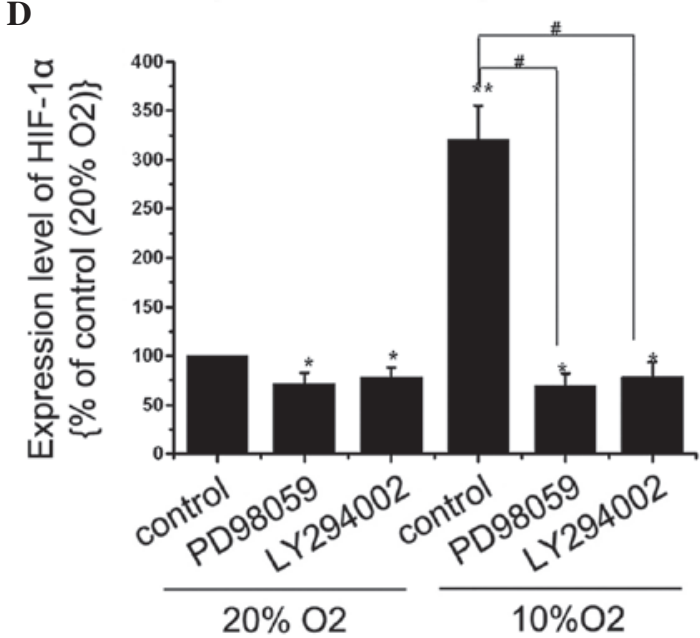

Figure 4. Mitogen activated protein kinase/ERK and phosphoinositide 3-kinase/Akt pathways promote the expression of HIF-1 $\alpha$ under hypoxic conditions. (A) MC3T3-E1 cells were cultured in 20,10,5 or $0 \% \mathrm{O}_{2}$ for $48 \mathrm{~h}$ and the expression levels of ERK, p-ERK, Akt and p-Akt were determined by western blot analysis. (B) Results represent three independent experiments. $\beta$-actin was used as loading control. ( ${ }^{* *} \mathrm{P}<0.01$ and ${ }^{\#} \mathrm{P}<0.01$, vs. 20\% $\mathrm{O}_{2}$ group). (C) Cells were cultured with or without $10 \mu \mathrm{M}$ PD98059 or $10 \mu \mathrm{M}$ LY294002 under 20 or $10 \% \mathrm{O}_{2}$, respectively, and the expression of HIF-1 $\alpha$ was determined by western blot analysis. (D) Results represent three independent experiments. $\beta$-actin was used as loading control. Values are expressed as the mean \pm standard error of the mean. ${ }^{*} \mathrm{P}<0.05$ and ${ }^{* *} \mathrm{P}<0.01$, vs. $20 \% \mathrm{O}_{2}$ control group; ${ }^{~} \mathrm{P}<0.01$, vs. $10 \% \mathrm{O}_{2}$ control group. ERK, extracellular signal-regulated kinase; p-, phosphorylated; HIF, hypoxia-inducible factor.

Based on the western blot analysis results, a low level of hypoxia significantly increased the activation of p-Akt and p-ERK, while severe hypoxia inhibited the PI3K/Akt and MAPK/ERK pathways. To assess whether the low level hypoxia-induced activation of ERK or Akt specifically regulated the expression of HIF-1 $\alpha$, the ERK pathway was suppressed using PD98059, an inhibitor of the upstream ERK regulator, MEK1/2. The PI3K/Akt pathway was inhibited using an LY294002 PI3K inhibitor. The LY294002 (10 $\mu \mathrm{M})(12)$ markedly decreased the activation of p-Akt and the expression of HIF-1 $\alpha$ (Fig. 4C) and PD98059 $(10 \mu \mathrm{M})(13)$, had a similar effect on the expression of HIF-1 $\alpha$, indicating that the hypoxia-induced increased expression of HIF-1 $\alpha$ in the MC3T3-E1 cells may be mediated by the $\mathrm{PI} 3 \mathrm{~K} / \mathrm{Akt}$ and MAPK/ERK pathways.

\section{Discussion}

Oxygen is essential for life, however, there are multiple physiological and pathological contexts in which cells experience conditions of hypoxia. As a negative stimulus, hypoxia can inhibit cell growth, promote apoptosis and promote tumor cell invasion (14). Additionally, hypoxia also initiates its own defense system. During hypoxia, tissues undergo a series of physiological responses to defend themselves against a reduced oxygen supply, including increased angiogenesis, erythropoiesis and glucose uptake (15). Whether hypoxia acts as a positive stimulus to promote cell proliferation remains to be elucidated. The present study revealed that low levels of hypoxia $\left(10\right.$ or $\left.5 \% \mathrm{O}_{2}\right)$ promoted cell proliferation and severe hypoxia $\left(1\right.$ or $\left.0 \% \mathrm{O}_{2}\right)$ induced apoptotic changes in the MC3T3-E1 cells. Low levels of hypoxia $\left(10 \% \mathrm{O}_{2}\right)$ increased the number of cells in the $\mathrm{S}$ phase of the cell cycle compared with the normoxic group and reduced the occurrence of G1 arrest. Thus, hypoxia also had certain positive effects, similar to the results of a previous study, which observed hypoxia enhanced the therapeutic effect of mesenchymal stem cells in renal ischemia/reperfusion injury by promoting paracrine action and improving their anti-apoptotic ability $(16,17)$.

The effects of hypoxia in a number of tissue and cell types are mediated primarily by HIF-1. HIF-1 is a heterodimer 
comprised of HIF- $\alpha$ subunits and a stable HIF-1 $\beta$ subunit. Whereas HIF-1 $\beta$ is expressed in cells, the expression of HIF-1 $\alpha$ is regulated by oxygen levels $(18,19)$. HIF- $1 \alpha$ is stimulated by low intracellular oxygen or genetic alteration and has been extensively investigated as an endogenous marker of hypoxia (20). The results from the present study demonstrated that HIF-1 $\alpha$ was involved in the proliferation of the MC3T3-E1 cells under hypoxic conditions. Overexpression of HIF-1 $\alpha$ increased the effect of hypoxia-induced cell proliferation, while HIF-1 $\alpha$-knockdown reversed the hypoxic effect. In addition, the PI3K/Akt and MAPK/ERK pathways contributed to regulating the expression of HIF-1 $\alpha$ under hypoxic conditions. The present study investigated how to effectively utilize the benefits of low $\mathrm{O}_{2}$ concentrations, overcome the hazards of high $\mathrm{O}_{2}$ concentrations $(21,22)$ and incorporate the positive role of HIF-1 $\alpha$, to provide a novel direction in the treatment of osteoporosis.

In conclusion, the present study demonstrated that hypoxia activates HIF-1 $\alpha$ through the PI3K/Akt and MAPK/ERK pathways and enhances cell proliferation in MC3T3-E1 cells. These findings suggested that low levels of hypoxia may have a beneficial role in osteoblast proliferation and that combined treatment with HIF-1 inhibitors under specific concentrations of oxygen, in a well optimized manner, may provide an important, beneficial, therapeutic approach in osteoporosis. Hypoxia, rather than acting as an 'on-off' switch for the hypoxic response as once hypothesized, initiates a complex cellular response involving multiple factors, including HIF-1, and requires further investigation.

\section{References}

1. Hadji P, Klein S, Gothe H, Häussler B, Kless T, Schmidt T, Steinle T, Verheyen F and Linder R:The epidemiology of osteoporosis - Bone Evaluation Study (BEST): an analysis of routine health insurance data. Dtsch Arztebl Int 110: 52-57, 2013.

2. Kanis JA, McCloskey EV, Johansson H, Oden A, Melton LJ 3rd and Khaltaev N: A reference standard for the description of osteoporosis. Bone 42: 467-475, 2008.

3. Riggs BL and Melton LJ 3rd: The worldwide problem of osteoporosis: Insights afforded by epidemiology. Bone 17: 505S-511S, 1995.

4. Soleymanian A, Niknami S, Hajizadeh E, Shojaeizadeh D and Montazeri A: Development and validation of a health belief model based instrument for measuring factors influencing exercise behaviors to prevent osteoporosis in pre-menopausal women (HOPE). BMC Musculoskelet Disord 15: 61, 2014.

5. Muz B, Khan MN, Kiriakidis S and Paleolog EM: Hypoxia. The role of hypoxia and HIF-dependent signalling events in rheumatoid arthritis. Arthritis Res Ther 11: 201, 2009.

6. Scherbakov AM,StefanovaLB, YakushinaIA and Krasilnikov MA: Beta-catenin signaling pathway and the tolerance of breast cancer cells to hypoxic conditions. Klin Lab Diagn 10: 68-70, 2013.
7. Liu SS, Wang HY, Tang JM and Zhou XM: Hypoxia-induced collagen synthesis of human lung fibroblasts by activating the angiotensin system. Int J Mol Sci 14: 24029-24045, 2013.

8. Banasiak KJ and Haddad GG: Hypoxia-induced apoptosis: effect of hypoxic severity and role of p53 in neuronal cell death. Brain Res 797: 295-304, 1998.

9. Calzado MA, de la Vega L, Möller A, Bowtell DD and Schmitz ML: An inducible autoregulatory loop between HIPK2 and Siah2 at the apex of the hypoxic response. Nat Cell Biol 11: 85-91, 2009.

10. Yang XM, Wang YS, Zhang J, Li Y, Xu JF, Zhu J, Zhao W, Chu DK and Wiedemann P: Role of PI3K/Akt and MEK/ERK in mediating hypoxia-induced expression of HIF-1alpha and VEGF in laser-induced rat choroidal neovascularization. Invest Ophthalmol Vis Sci 50: 1873-1879, 2009.

11. Moon EJ, Sonveaux P, Porporato PE, Danhier P, Gallez B, Batinic-Haberle I, Nien YC, Schroeder T and Dewhirst MW: NADPH oxidase-mediated reactive oxygen species production activates hypoxia-inducible factor-1 (HIF-1) via the ERK pathway after hyperthermia treatment. Proc Natl Acad Sci USA 107: 20477-20482, 2010.

12. Fujita T, Azuma Y, Fukuyama R, Hattori Y, Yoshida C, Koida M, Ogita $\mathrm{K}$ and Komori T: Runx2 induces osteoblast and chondrocyte differentiation and enhances their migration by coupling with PI3K-Akt signaling. J Cell Biol 166: 85-95, 2004.

13. Zhang LY, Zhou YY, Chen F, Wang B, Li J, Deng YW, Liu WD,Wang ZG, Li YW, Li DZ, Lv GH and Yin BL: Taurine inhibits serum deprivation-induced osteoblast apoptosis via the taurine transporter/ERK signaling pathway. Braz J Med Biol Res 44: 618-623, 2011.

14. He X, Brenchley PE, Jayson GC, Hampson L, Davies J and Hampson IN: Hypoxia increases heparanase-dependent tumor cell invasion, which can be inhibited by antiheparanase antibodies. Cancer Res 64: 3928-3933, 2004.

15. Shao Y and Zhao FQ: Emerging evidence of the physiological role of hypoxia in mammary development and lactation. J Anim Sci Biotechnol 5: 9, 2014.

16. Ding X, Lu C, Liu H, Rao S, Cai J, Liu S, Kriegel AJ, Greene AS, Liang $M$ and Ding X: Hypoxic preconditioning with cobalt of bone marrow mesenchymal stem cells improves cell migration and enhances therapy for treatment of ischemic acute kidney injury. PLoS One 8: e62703, 2013.

17. Hu S, Yan G, Xu H, He W, Liu Z and Ma G: Hypoxic preconditioning increases survival of cardiac progenitor cells via the Pim-1 kinase-mediated anti-apoptotic effect. Circ J 78: 724-731, 2014.

18. Semenza GL: Hypoxia-inducible factors in physiology and medicine. Cell 148: 399-408, 2012.

19. Liu Y, Ma Z, Zhao C, Wang Y, Wu G, Xiao J, McClain CJ, Li $X$ and Feng W: HIF- $1 \alpha$ and HIF- $2 \alpha$ are critically involved in hypoxia-induced lipid accumulation in hepatocytes through reducing PGC- $1 \alpha$-mediated fatty acid $\beta$-oxidation. Toxicol Lett 226: 117-123, 2014

20. Tsai YP and Wu KJ: Hypoxia-regulated target genes implicated in tumor metastasis. J Biomed Sci 19: 102, 2012.

21. Al-Motabagani MA: Histological changes in the alveolar structure of the rat lung after exposure to hyperoxia. Ital J Anat Embryol 110: 209-223, 2005.

22. Wang X, Wang Y, Kim HP, Nakahira K, Ryter SW and Choi AM. Carbon monoxide protects against hyperoxia-induced endothelial cell apoptosis by inhibiting reactive oxygen species formation. J Biol Chem 282: 1718-1726, 2007. 